Voon Hoong Fong, MD

Mohd Razif Mohamad Yunus, MBBS, MS (ORL-HNS)

Department of Otorhinolaryngology Head and Neck Surgery

Faculty of Medicine

Universiti Kebangsaan Malaysia Medical Centre

Kuala Lumpur, Malaysia
Correspondence: Dr. Voon Hoong Fong Department of Otorhinolaryngology Head and Neck Surgery

Faculty of Medicine

Universiti Kebangsaan Malaysia Medical Centre

Jalan Yaakob Latiff, Bandar Tun Razak 56000

Cheras, Kuala Lumpur, Malaysia

Phone: (+601) 26136564

Fax: (+603) 91456675

Email: daihoong@yahoo.com

Reprints will not be available from the authors.

The authors declared that this represents original material that is not being considered for publication or has not been published or accepted for publication elsewhere, in full or in part, in print or electronic media; that the manuscript has been read and approved by all the authors, that the requirements for authorship have been met by each author, and that each author believes that the manuscript represents honest work.

Disclosures: The authors signed disclosures that there are no financial or other (including personal) relationships, intellectual passion, political or religious beliefs, and institutional affiliations that might lead to a conflict of interest.

\section{Juvenile Angiofibroma Protruding from the Nasal Cavity}

\begin{abstract}
Objective: To describe a case of juvenile angiofibroma with unusual protrusion out of the nasal cavity, and its management with surgery and radiotherapy.
\end{abstract}

\section{Methods:}

\author{
Design: Case Report \\ Setting: Tertiary Public Referral Centre \\ Patient: One
}

Results: A 17-year-old gentleman presented with a huge tumor protruding from his left nostril, diagnosed with juvenile angiofibroma stage IIIA by MRI and angiography. Following successful pre-operative embolization, the protruding mass was ligated and truncated, followed by surgical resection via external approach. Post-operative residual tumor was treated with adjuvant radiotherapy. There was no evidence of recurrence after nine months.

Conclusion: A high index of suspicion is of paramount importance in the diagnosis of JA and avoids the possibility of an unwarranted biopsy which could spell disaster. The most useful tools for diagnosis are MRI and arterial angiography. Treatment is primarily surgical. Irradiation therapy has been reported to achieve satisfactory outcomes, especially for unresectable residual disease and/or intracranial extension, where total surgical resection is unlikely to be attained without unacceptable morbidity.

Keywords: Juvenile Angiofibroma, Juvenile Nasopharyngeal Angiofibroma, head and neck tumor

Juvenile Angiofibroma (JA) is a benign, highly vascular neoplasm affecting primarily male adolescents ${ }^{1}$ and accounts for $0.5 \%$ of all head and neck tumors. ${ }^{2}$ It often originates from the superior margin of the sphenopalatine foramen. ${ }^{3}$ The tumor may extend backwards into the nasal cavity and nasopharynx, laterally to the pterygopalatine fossa, involving the paranasal sinuses and infratemporal fossa. It may even invade the skull base and extend to cavernous sinus and pituitary fossa. ${ }^{4}$ The common clinical features include recurrent epistaxis and persistent nasal obstruction. ${ }^{5}$ We report a case of JA with unusual protrusion out of the nasal cavity. 


\section{CASE REPORT}

A 17-year-old Sabahan man presented with a one-year history of left nasal obstruction with recurrent epistaxis. Examination revealed a brownish well defined mass measuring $6 \times 5 \mathrm{~cm}$ protruding from his left nostril (Figure 1). The rest of the physical examination was noncontributory.

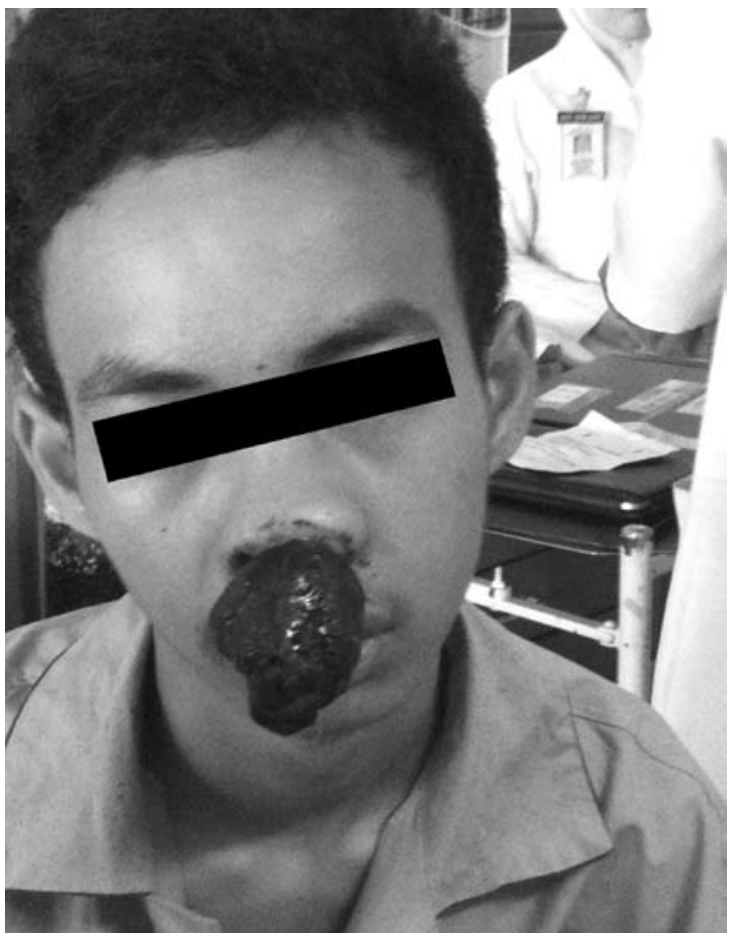

Figure 1. Tumor protruding from the left nostril.

Contrast-enhanced computed tomography (CT) scan showed a heterogenous mass occupying the left pterygopalatine fossa with anterior extension through the left nasal cavity protruding through the nose, lateral extension to the left infratemporal fossa, superior extension to the left ethmoidal and sphenoidal sinuses as well as the posterior part of the left orbit. (Figure 2) Magnetic resonance imaging (MRI) further characterized the tumor as an enhancing mass with small intracranial extension to left middle cranial fossa and dural involvement. (Figure 3) The radiographic features were suggestive of JA.

Angiography of both internal (ICA) and external carotid artery (ECA) revealed the tumor supplied by branches of both ICA and maxillary arteries from both ECA. Seventy percent (70\%) of the tumor-feeding vessels were successfully embolized. Figure $4 A$ and $B$ shows the arteriogram before and after embolization.

The definitive surgical procedure was performed the next day. The external nasal mass was first ligated and truncated from the nose. The internal portion of the tumor was resected via a Weber Ferguson

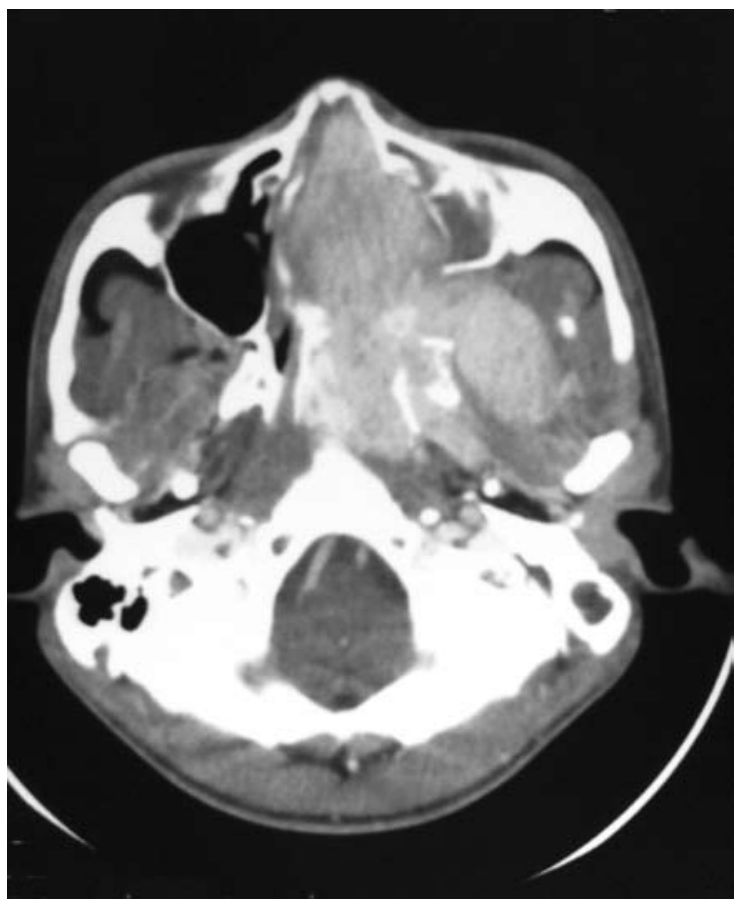

Figure 2. Contrast CT scan (axial view) revealing the extent of the disease.

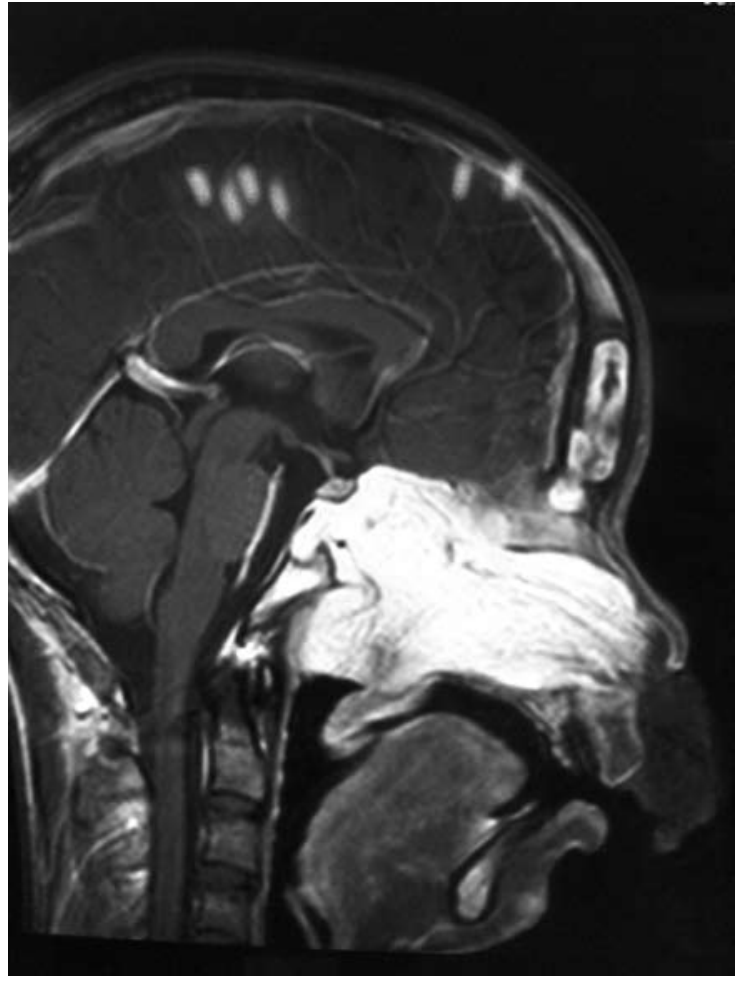

Figure 3. MRI scan characterizing the tumor and showing intracranial involvement 

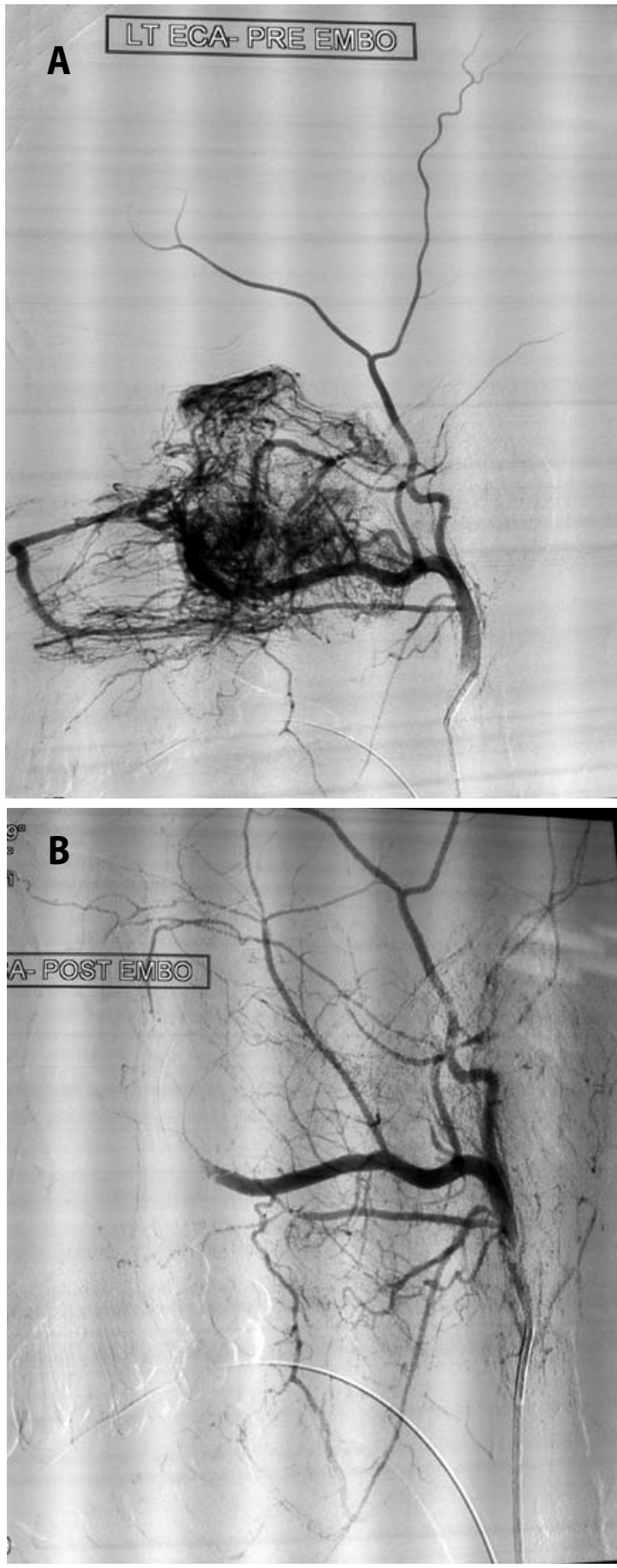

Figure 4. Angiograms- A, Pre-embolization; B, Post-embolization.

incision and canine approach. He made an uneventful recovery. Histopathological examination showed that the tumor was made up of variably sized blood vessels set in a delicate fibrocollagenous background, consistent with JA. A post-operative CT scan showed residual enhancing mass in the left pterygopalatine fossa, infratemporal fossa, sphenoid sinus, and superior orbital fissure. He subsequently

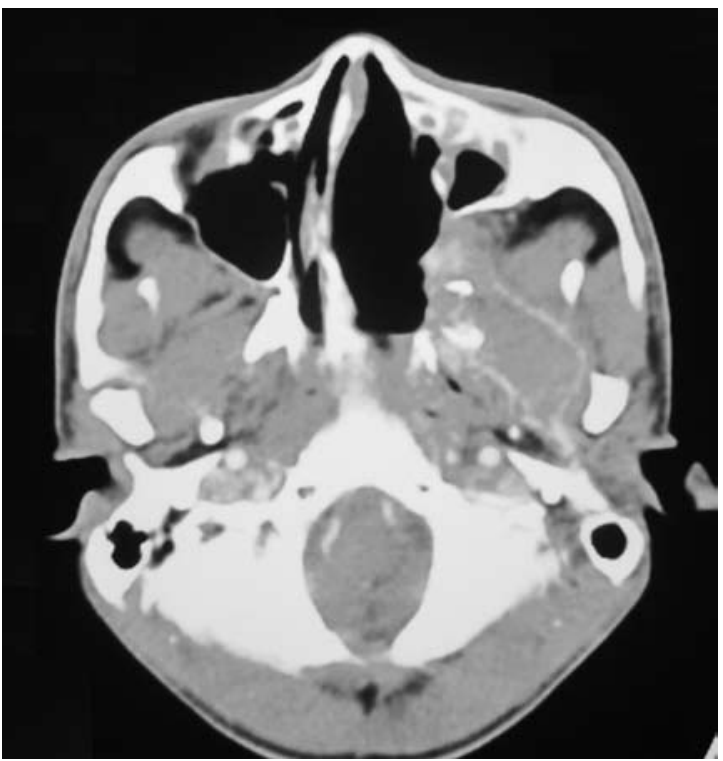

Figure 5. Post-radiotherapy $\mathrm{CT}$ scan (axial view) revealing no evidence of recurrence.

received 50Gy radiotherapy given in 25 fractions over five weeks which eradicated the residual lesion. At nine months post-irradiation, nasal endoscopy and CT scan revealed no recurrence. (Figure 5)

\section{DISCUSSION}

The diagnosis of JA was almost certain in view of the patient's gender, age and clinical presentation. A tumor protruding from the nasal cavity can be very tempting for a tissue biopsy, but doing so in an unprepared circumstance could spell disaster. The diagnosis could have been easily missed were it not for the initial evaluation with imaging studies because JA does not usually present as a mass protruding from the nose. Angiography further established the diagnosis and allowed embolization to be done in the same setting,

The Fisch ${ }^{6}$ classification (Table 1) has been commonly used for staging the disease. There are three other commonly employed staging systems (Table 2) ${ }^{7-9}$ None of these classifications mention tumor extension out of the nostril.

Staging is important to the surgeon to predict the outcome, to ascertain the chance of complete excision as well as to determine the approach to tumor resection. Not counting the extranasal tumor extension, the patient in this case was stage IIIA based on Radkowski classification. He underwent selective angiography to establish a definite diagnosis and to embolize the feeding vessels. This method has been widely recognized to reduce intraoperative blood loss which in turn facilitates the removal of tumor. ${ }^{10}$ Ungkanont et al. reported in a study with 43 cases that morbidity, recurrence and intraoperative complications decreased with embolization. ${ }^{11}$ However, there are several risks of embolization including bleeding, allergic reactions and 


\section{CASE REPORTS}

Table 1. Stages of the Fisch classification ${ }^{6}$

\begin{tabular}{|c|l|}
\hline Stage & \multicolumn{1}{|c|}{ Description } \\
\hline I & $\begin{array}{l}\text { Tumors limited to the nasal cavity nasopharynx with no } \\
\text { bony destruction. }\end{array}$ \\
\hline II & $\begin{array}{l}\text { Tumors invading the pterygomaxillary fossa, paranasal } \\
\text { sinuses with bony destruction. }\end{array}$ \\
\hline III & $\begin{array}{l}\text { Tumors invading the infratemporal fossa, orbit and } \\
\text { parasellar region remaining lateral to the cavernous } \\
\text { sinus. }\end{array}$ \\
\hline IV & $\begin{array}{l}\text { Tumors with invasion to the cavernous sinus, optic } \\
\text { chiasmal region and pituitary fossa. }\end{array}$ \\
\hline
\end{tabular}

Table 2. Other staging systems for juvenile angiofibroma

\section{Chandler et al, $1984^{7}$}

II Tumor extending into nasal cavity or sphenoid sinus

III Tumor extending into antrum, ethmoid sinus, PMF, orbit, and/or cheek

IV Intracranial tumor

\section{Sessions et al, $1981^{8}$}

\begin{tabular}{l|l|} 
IA & Limited to nose and/or nasopharyngeal vault \\
IB & Extension into $\geq 1$ sinus \\
IIA & Minimal extension into PMF \\
IIB & Full occupation of PMF with or without erosion of orbital \\
& bones \\
IIC & Infratemporal fossa with or without cheek erosion \\
III & Intracranial extension
\end{tabular}

Radkowski et al, $1996^{\circ}$

\begin{tabular}{l|l} 
IA & Limited to nose and/or nasopharyngeal vault \\
IB & Extension into $\geq 1$ sinus \\
IIA & Minimal extension into PMF \\
IIB & $\begin{array}{l}\text { Full occupation of PMF with or without erosion of orbital } \\
\text { bones }\end{array}$ \\
IIC & $\begin{array}{l}\text { Or posterior to pterygoid plates } \\
\text { IIIA }\end{array}$ \\
IIIB & $\begin{array}{l}\text { Erosion of skull base - minimal intracranial extension } \\
\text { Erosion of skull base - extensive intracranial extension } \\
\text { with or without cavernous sinus invasion }\end{array}$ \\
\hline
\end{tabular}

strokes. The patient in this case was free from these complications.

There are several modalities of treatment for $\mathrm{JA}$, with surgical resection and irradiation therapy being the most successful. It is generally accepted that surgery is the treatment of choice while radiotherapy is best for recurrence post surgery or extensive tumor with significant intracranial extension (where total resection with acceptable morbidity is unlikely). There is also a relatively large series of 55 patients with $\mathrm{JA}$, where 42 underwent radiotherapy as the primary therapy and $80 \%$ were successfully treated..$^{12}$

Surgical resection was essential for the patient in this case because he had a huge tumor protruding from his nostril, which was unlikely to regress with other treatments. It is also generally accepted that external approaches are superior in advanced tumors. ${ }^{13}$ In view of the tumor extent, the open approach was adopted. However, resection was incomplete due to intracranial extension. Hence, adjuvant radiotherapy was given for residual disease. Mendenhall et al. summarized six studies on the outcome of radiotherapy for JA. ${ }^{5}$ Most patients in these series were those who exhibited recurrence after prior surgery or had intracranial extension. After completing radiotherapy, local control rates ranged from $73 \%$ to $100 \%$. Almost all those with recurrence after radiotherapy were successfully treated with another surgery or a second course of radiotherapy. Hence, the ultimate local control was nearly $100 \%$.

Our case shows that a high index of suspicion is of paramount importance in the diagnosis of JA and alleviates the possibility of an unwarranted biopsy, as an indiscriminate biopsy could spell disaster. The most useful tools are MRI and arterial angiography. Once the definite diagnosis is established, the treatment plan has to be mapped out which is primarily surgical. Irradiation therapy has been reported to achieve satisfactory outcome, especially for unresectable residual disease and/or intracranial extension, where total surgical resection is unlikely to be attained without unacceptable morbidity.

\section{REFERENCES}

1. Tang IP, Shashinder S, Gopala Krishnan G, Narayanan P. Juvenile nasopharyngeal angiofibroma in a tertiary centre: ten-year experience. Singapore Med J 2009 Mar;50(3): 261-264.

2. Bales C, Kotapka M, Loevner LA, Al-Rawi M, Weinstein G, Hurst R, et al. Craniofacial resection of advanced juvenile nasopharyngeal angiofibroma. Arch Otolaryngol Head Neck Surg 2002 Sep;128(9):1071-1078.

3. Sennes LU, Butugan O, Sanchez TG, Bento RF, Tsuji DH. Juvenile nasopharyngeal angiofibroma: the routes of invasion. Rhinology $2003 \mathrm{Dec} ; 41(4): 235-40$.

4. TewfikTL,Tan AK, al Noury K, Chowdhury K, Tampieri D, Raymond J, et al. Juvenile nasopharyngeal angiofibroma. J Otolaryngol 1999 Jun;28(3):145-51.

5. Mendenhall WM, Werning JW, Hinerman RW, Amdur RJ, Villaret DB. Juvenile nasopharyngeal angiofibroma. J HK Coll Radiol 2003;6(1):15-19.

6. Andrews JC, Fisch U, Valavanis A, Aeppli U, Makek MS. The surgical management of extensive nasopharyngeal angiofibromas with the infratemporal fossa approach. Laryngoscope 1989 Apr;99(4):429-37.

7. Chandler JR, Goulding R, Moskowitz L, Quencer RM. Nasopharyngeal angiofibromas: staging and management. Ann Otol Rhinol Laryngol 1984 Jul-Aug;93(4 Pt 1):322-9.

8. Sessions RB, Bryan RN, Naclerio RM, Alford BR. Radiographic staging of juvenile angiofibroma. Head Neck Surg Mar-Apr;3(4):279-83.

9. Radkowski D, McGill T, Healy GB, Ohlms L, Jones DT. Angiofibroma. Changes in staging and treatment. Arch Otolaryngol Head Neck Surg 1996 Feb;122(2):122-129.

10. Mann WJ, Jecker P, Amedee RG. Juvenile angiofibromas: changing surgical concept over the last 20 years. Laryngoscope 2004 Feb;114(2):291-3.

11. Ungkanont K, Byers RM, Weber RS, Callender DL, Wolf PF, Goepfert $\mathrm{H}$. Juvenile nasopharyngeal angiofibroma: an update of therapeutic management. Head Neck 1996 Jan-Feb;18(1):60-6.

12. Cummings BJ, Blend R, Keane T, Fitzpatrick P, Beale F, Clark R et al. Primary radiation therapy for juvenile nasopharyngeal angiofibroma. Laryngoscope 1984 Dec;94(12 Pt 1):1599-605.

13. Nicolai P, Berlucchi M, Tomenzoli D, Cappiello J, Trimarchi M, Maroldi R, et al. Endoscopic surgery for juvenile angiofibroma: when and how. Laryngoscope 2003 May;113(5):775-82. 